\title{
On the performance of a small out-pipe inspection mobile robot for chemical industry
}

\begin{abstract}
This invention relates to a pipe tracking device which can detect gas leak with offline monitoring based real-time system which displayed by LCD. This device dedicated as gas leak detector at companies that utilize the pipeline as a tool for gas distribution, such as chemical-industry, gas-industry, etc. This inspector robot type is "out-pipe mobile robot". There are two main parts, the sensor and the mechanic. It use ultrasonic sensor as tracking object (straight or curve) and gas sensors to detect the presence of dangerous gas which mixed in air due to leakage. In mechanical aspect, we design mobile robot with small size and support the best maneuver.
\end{abstract}

Keywords: gas pipe, out-pipe inspection, mobile robot, real-time monitoring, offline
Volume 2 Issue 5 - 2017

\author{
Syifaul Fuada \\ Bandung Institute of Technology, University Center of Excellence \\ on Microelectronics, Indonesia
}

Correspondence: Syifaul Fuada, Bandung Institute of Technology, University Center of Excellence on Microelectronics, Indonesia, Tel +62-22-2506280, Fax +62-222508763, Email syifaulfuada@pme.itb.ac.id

Received: June 26, 2017| Published: July 12, 2017

\section{Introduction}

Over the past 3 decades, the wheeled mobile robots have been an interesting and active area of automous system research, development and deployment. Related research is done by Majmudar et al., ${ }^{1}$ which design about vision system for door sensing based mobile robots. Other research is done by Nicolas et al., ${ }^{2}$ which develop mobile robot systems for following and people tracking purpose with big size. Then Sharifi et al., ${ }^{3}$ design mobile robot which dedicated for indoor localization based visible light. There are a lot of researches about mobile robot for various applications. Pipe as the main medium of gas transportation has various forms of applications. ${ }^{4}$ Inspection become a regular activities performed by chemical industries that aim to prevent several things which out of control, eg. gas leakage (due to pipes corrosion or other things beyond estimates). There are three common technologies which can be applied. Basically those three devices should be held by chemical industries in order to cover the dangers and complement technology each other. First is inspection from inpipe using autonomous robot. This tool commonly called in-pipe mobile robot. ${ }^{5-10}$ The advantages point, the inspector can determine condition of pipe by real-time which grounded even in under of sea. But it requires a good device to able to work in harsh environment. Second is inspection from out-pipe with tracking method at the pipe to know whether any cracks. This activity can be covered by human (trace the stretch pipe with a specific tool) or by mobile robot which patch on the pipe (e.g. climbing robot ${ }^{11,12}$ ). Third is a mobile robot which specific task of detecting leakage gas only. ${ }^{13,14}$ We are know that the risk of leakage suddenly although just little have a significant effect on living things including human who work in the venue.

The focus of this invention is the third point, to make pipe tracking mobile as gas leak detector. Other research addressed in $\mathrm{Chia}^{15}$ which focus on control system optimization by PID algorithm and tested in wall medium with specific size. In this project we use pipe as the object for detect and it is similar with Harianto et al. ${ }^{16}$ robot platform which design Omni-directional robot to detect chemical gasses using electric nose technology. They use neural network artificial intelligence and according to the results. Their system can detect several different gasses with has similarity chemical characteristics. In this system we also use artificial intelligence system and embedded in the mobile robot. Different with Harianto ${ }^{16}$ that use omni wheel, we use circle wheel and free wheel placed at front of robot.

\section{System architecture}

The mobile robot (Figure 1) is consisting of: ultrasonic sensor, gas sensor, keypad, LCD, microcontroller and DC motor with gearbox. Each side of the mobile robot is mounted by ultrasonic sensors (on the right, ahead and left) which serve to explore the horizontal pipeline. The LCD (Figure 2a) (Figure 2b) is mounted above the robot for displaying several menu(s): input the data gas sensor calibration, proximity calibration and display sensing data. The mobile robot is driven by two wheels, namely free wheel which mounted in front and drive wheel which mounted behind of the mobile robot. The two DC motors are driven by microcontroller for synchronizing the robot movement against terrain traversed. The algorithm syntax used by $\mathrm{C}$ programming.

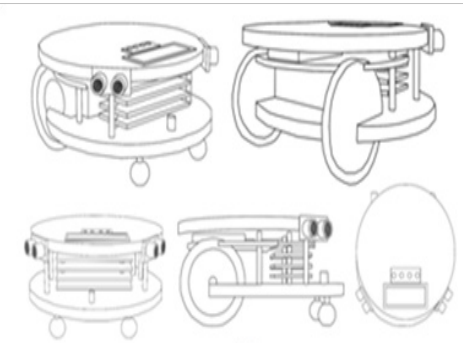

(a)

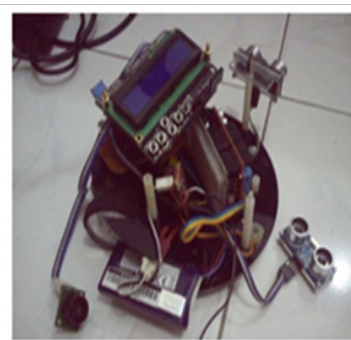

(b)
Figure I (a) A small out-pipe inspection mobile robot architecture; (b) Anatomy of out-pipe inspection mobile robot.

The mobile robot which has been developed has specifications as follows:

a. Offline monitoring, when the gas is detected in the pipe at specific area, the information will be indicated by a buzzer sound, moreover the mobile robot will be stopped. So far, the indicative data of a gas leak is displayed on LCD and buzzer. If an error occurs, the robot going to spin and emit sound continuously. Next target, we will develop robot with online monitoring version.

b. Ability, tracking the winding horizontal pipe, the mobile robot has a technology "pipe tracking algorithm" with a maximum distance between the pipes to the sensor by $0.5 \mathrm{~m}$. Then, able to detect a pipe with a diameter of $<30 \mathrm{~cm}$, because the height of sensor robot can be set manually. 
c. Unique anatomy, the mechanical construction of mobile robot is "round", therefore make it easier to maneuver while tracking of sharp bends object.

d. Dimension, small size about $15 \mathrm{~cm} \times 15 \mathrm{~cm}$.

e. Accuracy, the mobile robot can detect different types of gas containing $\mathrm{CO}_{2}$ with high accuracy, low noise and precision cause of specific analog processing circuit. It uses a reliable instrumentation amplifier.

f. Friendly user, easy to install and calibrate by everyone.

g. Sensitivity, the mobile robot can detect gas by $<5$ s and can compare sensing data with calibration data setting quickly.

h. Limitations, the mobile robot only trace a horizontal pipe and the field with has a hard ground (e.g. flat floor). Rocky, sandy and slope field is not acceptable. Moreover, has not equipped with graphical user interface (GUI) monitor.

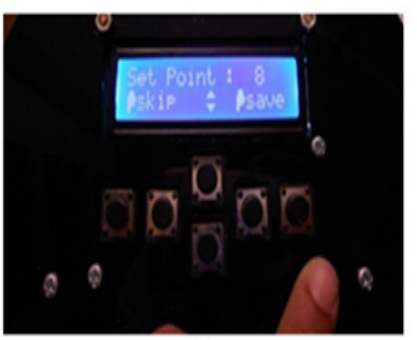

(a)

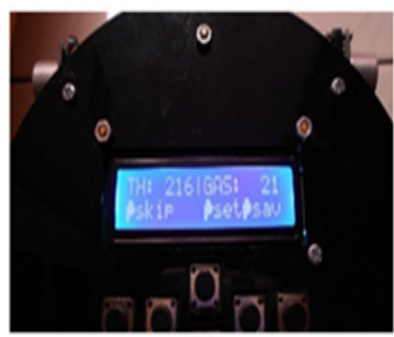

(b)
Figure 2 Mobile robot set-up: (a) setting point for proximity sensing of ultrasonic sensor; (b) setting point for gas sensing of gas sensor.
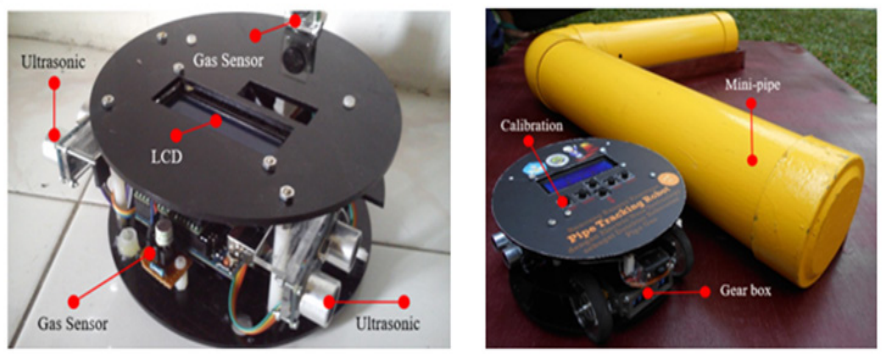

Figure $3 \mathrm{~A}$ small out-pipe inspection mobile robot product.

\section{Demonstration set-up}

The main characteristics of this out-pipe robot type is it can be developed with available components and affordable, e.g. material for casing and the microcontroller as brain of artificial intelligence system. Therefore, the sales value is in intelligent system algorithm, robot's capabilities in data processing and reliable of robot construction. This invention covers this factor. This invention is used as a tool which can replace human performance. The aim is to make better facilitate investigation of pipe condition which leaked at particular points. Furthermore, it will minimize the work accidents risk. As a commercial products commonly, the mobile robot come together with manual book to enable user in usage, with consist of calibration procedure and its technical applications. Each gas to be detected should be adjusted to minimum standard. We use a standard by Indonesian government regulations (KEP- 107/KABAPEDAL/11/1997). This invention Figure 3 is accommodate it the research product is shown in Figure 4, we have been patented the invention with No. 2016/S/00145 and for international patent with no I.P.C: Int.Cl./B 23D 45/00, C 12N 15/00, $15 / 82 .{ }^{17}$ Therefore, the technologies which embedded in this invention are hidden in order to maintain secrecy policy.

The robot is activated by Li-Po battery $12 \mathrm{~V}_{\mathrm{DC}}$. It will be demonstrated by manual with pushing the "on" button. Before it, the user must calibrate the mobile robot and conditioned in accordance with air condition (in specific room which installed air conditioner). Then the mini-pipe (replica industrial-pipe) sprayed toxic gas. Furthermore, the mobile robot tracking a stretch pipe, illustration of tracking object shown in Figure 5. The real-time sensing data which transmitted by the microcontroller is displayed by the LCD, the data i.e. Kp, Kd, Ki of PID controller parameters, ultrasonic sensors condition, gas condition and also leakage gas which detected. The buzzer will ring if detect toxic gas to inform that the pipe was leak.

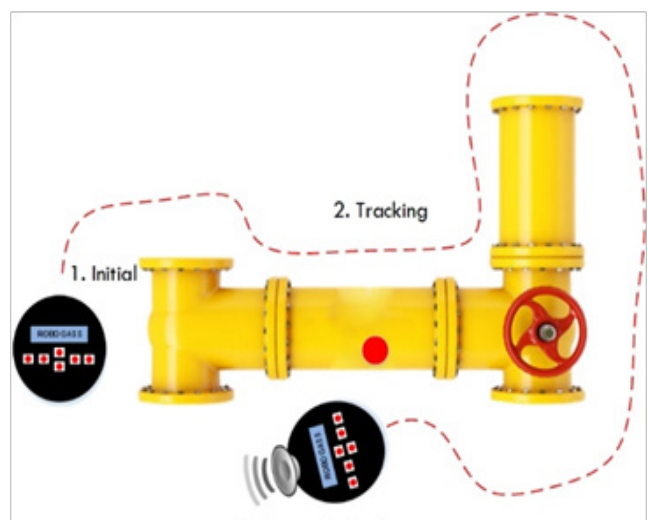

3. Detect the leakage gas

Figure 4 Demonstration setup of inspection mobile robot.
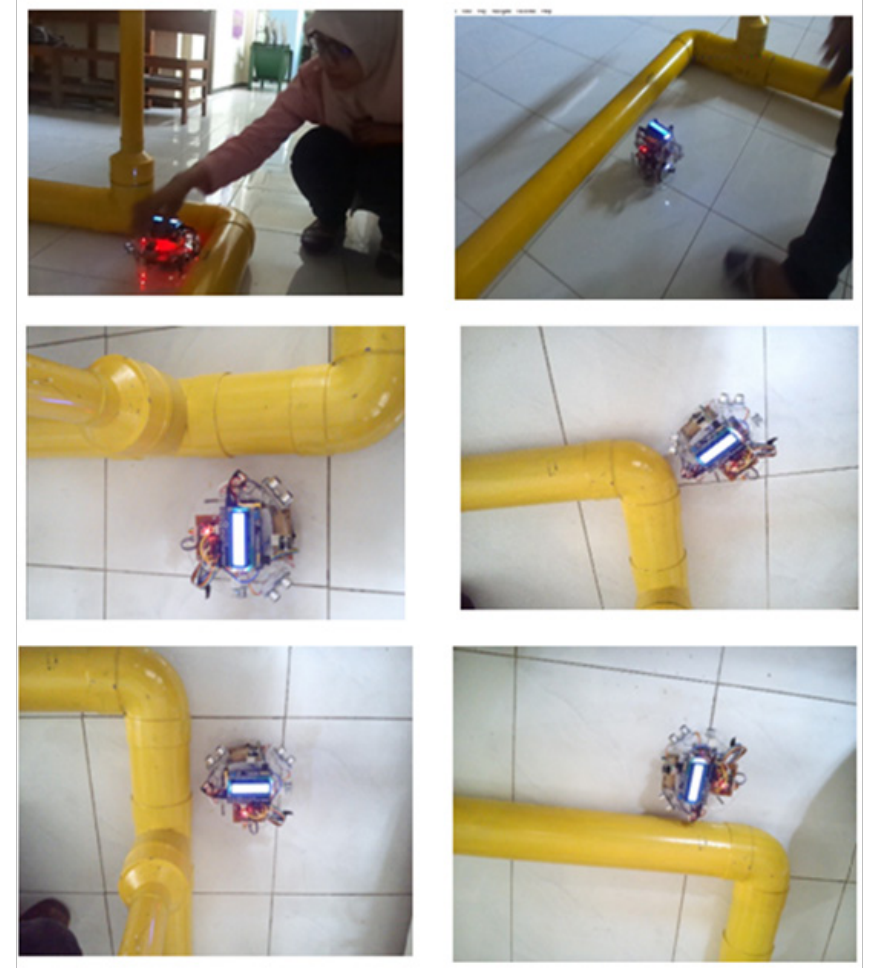

Figure $\mathbf{5}$ Inspection mobile robot was tracking the horizontal pipe. 
Table I Detail about mobile robot systems

\begin{tabular}{ll}
\hline Parameters & Values \\
\hline battery lithium polymer 2 cell & $1000 \mathrm{~mA}$ max. 7.4 Volt \\
Body acrylic & black $/ 16 \mathrm{~cm} / 3 \mathrm{~mm}$ \\
Wheels acrylic & transparent $/ 4,5 \mathrm{~mm} / 6 \mathrm{~mm}$ \\
Sensors & Toxic gas and ultrasonic \\
Display device & LCD \\
\hline
\end{tabular}

\section{Conclusion}

Pipe is the main media of gas transportation which has been widely used by many chemical industries. It is necessary a monitor activities periodically to know condition of gas pipeline. Because if there any leakage gas from the pipeline, it will make a loss material from these industries and also can contained the air quality. This invention is a mobile robot which is dedicated to explore the gas pipeline in order for indicating the leakage gas. For future research, we will integrate an online monitoring system. Therefore it is need GUI interface for observing real-time condition. Zigbee and Wi-Fi are recommended to be used in this mobile robot system. It will more attractive when monitoring device is performed by smartphone with specific mobile apps. Then, we plan to develop this robot as learning tool; however it must be validated by expert media and material. The process is likely discussed in Fuada. ${ }^{18}$

\section{Acknowledgments}

None.

\section{Conflict of interest}

Author declares that there is none of the conflicts.

\section{References}

1. Majumdar J, Jain RPK, Venkatesh GM, et al. Intelligent Vision System for Door Sensing Mobile Robot. Int J of Robotics and Automation (IJRA). 2012;1(4):190-202.

2. Olmedo NA, Zhang H, Lipsett M. Mobile robot system architecture for people tracking and following applications. Proc of the 2014 IEEE Int Conf on Robotics and Biometrics. 2014. p. 825-830.

3. Sharifi H, Akshaya Kumar, Fakrul Alam, et al. Indoor localization of mobile robot with visible light communication. Proc of the $12^{\text {th }}$ IEEE/ ASME Int Conf on Mechatronic and Embedded Systems and Applications (MESA). 2016

4. Fuada S. Studi Awal Pembuatan Robot Out-Pipe Tracking berbasis Neural Network. Proc of Simposium Fisika Nasional (SFN). 2013. p. 258-266.
5. Moghaddam. Design, Modeling and Prototyping of a Pipe Inspection Robot. Proc of the 22 $2^{\text {nd }}$ Int Symposium on Automation and Robotics in Construction (ISARC). 2005. p. 1-6.

6. Nayak A, Pradhan SK. Design of a New In Pipe Inspection Robot. Procedia Engineering. 2014;97:2081-2091.

7. Kim JH, Sharma G, Iyengar S. FAMPER: A Fully Autonomous Mobile Robot for Pipeline Exploration. Proc of IEEE Int Conf on Industrial Technology (ICIT). 2010. p. 517-523.

8. Kwon YS, B Lee, Whang IC, et al. A Flat Pipeline Inspection Robot with Two Wheel Chains. Proc of the 2011 IEEE Int Conf on Robotics and Automation. 2011. p. 5141-5146.

9. Chang FS, Hwang LT, Liu CF, et al. Design of a pipeline inspection robot with belt driven ridged cone shaped skate model. Proc of the 2015 IEEE Conf on Robotics and Biomimetics. 2015. p. 787-792.

10. Prasad EN, Kannan M, Azarudeen A, et al. Defect Identification In Pipe Lines Using Pipe Inspection Robot. Int J of Mechanical Engineering and Robotic Research (IJMERR). 2012;1(2):20-31.

11. Han SC, An J, Moon H. A Remotely Controlled Out-Pipe Climbing Robot. Proc of the $201310^{\text {th }}$ Int Conf on Ubiquitous Robots and Ambient Intelligence (URAI). 2013. p. 126.

12. Liu KP, Luk BL, Chan YT. Service Robot for Inspecting Exterior Gas Pipes of High Rise Buildings. Proc of the World Congress on Engineering. 2009;2:1550-1554.

13. Anindya C, Fuada S, Firmansyah S, et al. Rancang Bangun Prototype Robot Pipe Tracking dengan Electric Nose Technology Sebagai Detektor Kebocoran. Proc of Program Kreativitas Mahasiswa Karsa Cipta. 2014. p. $1-4$.

14. Anindya C, Fuada S, Firmansyah S, et al. Prototyping of the Pipe Tracking Robot Using Electronic Nose Technology as Gas Leakage Detector. Int $J$ of Engineering Research and Development (IJERD). 2014;10(9):1-5.

15. Chia KS, Yap XY. A Portable PID Control Learning Tool by Means of a Mobile Robot. IJOE. 2016;12(6):54-57.

16. Harianto, Rivai M, Purwanto D. Implementation of Electronic Nose in Omni-directional Robot. Int J of Electrical and Computer Engineering (IJECE). 2013;3(3):399-406.

17. Berita Resmi Paten Sederhana SERI-A. No. BRP480/S/III/2016 Diumumkan Tanggal 18 Maret 2016 s/d 18 JUNI 2016. Pengumuman Berlangsung Selama 3 (TIGA) Bulan Sesuai Dengan Ketentuan Pasal 44 Ayat (1) Undang-Undang Paten Nomor. 2016. p. 1-32.

18. Fuada. Pengujian Validitas Alat Peraga Pembangkit Sinyal (Oscillator) untuk Pembelajaran Workshop Instrumentasi Industri. Proc of Seminar Nasional Pendidikan (SEMNASDIK). 2015. p. 854-861. 